\title{
Sensibilidade de estirpes de Bradyrhizobium ao glyphosate
}

\author{
Rodrigo Josemar Seminoti Jacques ${ }^{1}$, Sérgio de Oliveira Procópio², José Barbosa dos Santos ${ }^{3}$, Maria Catarina \\ Megumi Kasuya ${ }^{4}$, Antônio Alberto da Silva ${ }^{5}$
}

\section{RESUMO}

A aplicação do glyphosate sobre a soja resistente a este herbicida pode causar prejuízos à simbiose com o rizóbio. O objetivo deste trabalho foi avaliar a sensibilidade ao herbicida glyphosate de três estirpes de Bradyrhizobium recomendadas para a produção de inoculantes de sementes de soja no Brasil. Avaliou-se o efeito das concentrações de 0,0; 5,4; 10,8; 21,6 e 43,2 $\mu \mathrm{g} \mathrm{L} \mathrm{L}^{-1}$ do ingrediente ativo do glyphosate [N-(fosfonometil) glicina] no meio YM líquido sobre o crescimento de B. japonicum (estirpe SEMIA 5079) e de B. elkanii (estirpe SEMIA 5019 e estirpe SEMIA 587), por meio de leituras das densidades óticas e geração de curvas de crescimento. As reduções de crescimento na presença da menor concentração do glyphosate foram de 18\% para SEMIA 5079, 29\% para SEMIA 5019 e de 35\% para SEMIA 587, sendo, de modo geral, quanto maior a concentração do herbicida no meio de cultura maior a inibição do crescimento. As estirpes apresentaram sensibilidade diferencial somente às concentrações mais baixas do glyphosate; nesse caso, foi possível determinar a seguinte ordem de sensibilidade: SEMIA 587 > SEMIA 5019 > SEMIA 5079. Essa sensibilidade diferencial é dependente da concentração do herbicida, pois na presença de 43,2 $\mu$ g L-1 todas as estirpes tiveram seu crescimento severamente reduzido, não havendo diferença entre elas.

Palavras-chave: Herbicida, soja, inoculante, rizóbio, EPSPs.

\section{ABSTRACT}

\section{Sensitivity of Bradyrhizobium strains to glyphosate}

Glyphosate applications to glyphosate-resistant soybean may impair symbiosis with Bradyrhizobium, a symbiotic bacterium. This study evaluated the sensitivity to glyphosate of three Bradyrhizobium strains used commercially in soybean crop in Brazil. The concentrations (0.0; 5.4; 10.8; 21.6 e $\left.43.2 \mu \mathrm{g} \mathrm{L}^{-1}\right)$ of the active ingredient glyphosate [N(phosphonomethyl)glycine] were added to YM liquid medium for the growth of one strain of B. japonicum (SEMIA 5079) and two strains of B. elkanni (SEMIA 5019 and SEMIA 587) inoculated as pure culture. The herbicide effect on the growth of the tested strains was assessed by optical density and growth curves were established for each strain. Reduction in growth of strains in the lowest glyphosate concentration were 18\% for SEMIA 5079, 29\% for SEMIA 5019 and 35\% for SEMIA 587. In general, the higher the concentration of the herbicide in the culture medium, the greater the growth inhibition. The strains showed differential sensitivity only at the lowest concentrations of glyphosate, allowing the determination of the following order of sensitivity: SEMIA 587>SEMIA 5019>SEMIA 5079. This differential sensitivity is dependent on the herbicide concentration, since in the presence of $43.2 \mu \mathrm{g} \mathrm{L}-1$ all strains severely reduced growth, not showing difference among them.

Key words: Herbicide, soybean, inoculant, rhizobium, EPSPs.

Recebido para publicação em novembro de 2008 e aprovado em setembro de 2009

${ }^{1}$ Engenheiro-Agrônomo, Doutor. Departamento de Solos, Universidade Federal de Santa Maria, Avenida Roraima, 1000, 971005-900, Santa Maria, Rio Grande do Sul, Brasil. rodrigosolos@yahoo.com.br

Engenheiro-Agrônomo, Doutor. Embrapa Tabuleiros Costeiros, Avevnida Beira Mar, 3250, 49025-040, Aracaju, Sergipe, Brasil. procopio@cpatc.embrapa.br

${ }^{3}$ Engenheiro-Agrônomo, Doutor. Departamento de Agronomia, Universidade Federal dos Vales do Jequitinhonha e Mucuri, Rodovia MGT 367, Km 583, 39100-000, Diamantina, Minas Gerais, Brasil. jbarbosa@ufvjm.edu.br

${ }^{4}$ Engenheira-Agrônoma, Doutora. Departamento de Microbiologia, Universidade Federal de Viçosa, Avenida Peter H. Rolfs, s/n, 36570-000, Viçosa, Minas Gerais. mkasuya@ufv.br

Engenheiro-Agrônomo, Doutor. Departamento de Fitotecnia, Universidade Federal de Viçosa, Avenida Peter H. Rolfs, s/n, 36570-000, Viçosa, Minas Gerais. aasilva@ufv.br 


\section{INTRODUÇÃO}

No Brasil, a soja é a cultura que ocupa a maior área de cultivo, sendo essa superior a 21 milhões de hectares na safra 2007/2008 (Embrapa, 2009). Com exceção dos cultivos orgânicos, os herbicidas são aplicados em praticamente toda essa área, fazendo com que a soja seja a cultura que tem o maior volume aplicado de herbicidas no País (Santos et al., 2005).

O glyphosate é um herbicida foliar, não seletivo, de amplo espectro, cujo modo de ação se dá pela inibição da enzima EPSPs (5-enolpiruvil-shiquimato-3-fosfato sintase, EC 2.5.1.19) das plantas, integrante da rota do shiquimato, que é responsável pela síntese dos aminoácidos aromáticos (Buchanan et al., 2000).

Os avanços biotecnológicos têm resultado no desenvolvimento de cultivares de soja resistentes ao glyphosate (RR), devido à inserção na planta de um gene da EPSPs insensível a este herbicida, oriundo da Agrobacterium CP4 (Padgette et al., 1995). Com isso, o glyphosate pode ser aplicado em pós-emergência sobre a cultura da soja $\mathrm{RR}$, levando à morte somente as plantas daninhas.

Apesar dos resultados técnico-econômicos positivos dessa prática, o glyphosate pode prejudicar o processo de fixação de $\mathrm{N}_{2}$ realizado pela simbiose da soja RR com as bactérias do gênero Bradyrhizobium (Eberbach \& Douglas, 1989; Reddy et al., 2000; King et al., 2001). Em vista da grande demanda de energia para a fixação de $\mathrm{N}_{2}$, os nódulos são considerados drenos de fotoassimilados. O glyphosate pode ser transportado pelo floema, juntamente com os fotoassimilados, até os nódulos e vir a ser tóxico às células do Bradyrhizobium, que possuem a enzima EPSPs sensível a esse herbicida (Hernandez et al., 1999). Porções de glyphosate presentes nos nódulos de soja RR foram quantificadas 14 dias após a aplicação desse herbicida, encontrando-se valor de $147 \mathrm{ng} \mathrm{g}^{-1}$ de massa seca (Reddy \& Zablotowicz, 2003).

Apesar dos já comprovados prejuízos do glyphosate ao crescimento dos rizóbios e de outros microrganismos do solo (Schulz et al., 1985; Moorman,1986; Santos et al., 2005; Zabaloy \& Gómez, 2005), poderá haver diferença entre as estirpes de Bradyrhizobium quanto à sensibilidade a esse herbicida (Mallik \& Tesfai, 1985; Hernandez et al., 1999). Esse comportamento também foi observado quando da avaliação do efeito de outros xenobióticos que não o glyphosate no crescimento do Bradyrhizobium (Borges et al., 1990; Arruda et al., 2001).

Alguns autores já recomendaram que a seleção de estirpes para uso em inoculantes de soja considere, além da característica de nodulação e de fixação de $\mathrm{N}_{2}$, a resistência aos pesticidas mais comumente utilizados na cul- tura (Borges et al., 1990). Assim, o objetivo deste trabalho foi avaliar a sensibilidade ao ingrediente ativo glyphosate de três estirpes de Bradyrhizobium, atualmente recomendadas para a produção de inoculantes de sementes de soja no Brasil.

\section{MATERIAL E MÉTODOS}

As estirpes de Bradyrhizobium elkanii SEMIA 587 e SEMIA 5019 e de B. japonicum SEMIA 5079 foram cedidas pelo Centro Nacional de Pesquisa de Agrobiologia/ EMBRAPA, sendo estocadas à temperatura de $4{ }^{\circ} \mathrm{C}$ em meio YM sólido, cuja composição é, em g L ${ }^{-1}$ : manitol, 10,$0 ; \mathrm{K}_{2} \mathrm{HPO}_{4}, 0,5 ; \mathrm{MgSO}_{4}, 0,2 ; \mathrm{NaCl}, 0,1$; extrato de levedura, 0,5; ágar, 15,0; e em pH, 6,8.

O experimento constituiu-se de um arranjo fatorial completo $3 \times 5$, sendo três estirpes de Bradyrhizobium e cinco concentrações de glyphosate em meio de cultura. Os 15 tratamentos foram dispostos em delineamento inteiramente casualizado, com seis repetições.

As soluções do glyphosate foram preparadas imediatamente antes do uso, mediante a mistura do ingrediente ativo $\mathrm{N}$-(fosfonometil) glicina (99\% de pureza) com água ultrapura (Milli- ${ }^{\circledR}$ ), sendo posteriormente esterilizadas por filtração (filtro Millipore ${ }^{\circledR}, 0,25 \mu \mathrm{m}$ ), em condições assépticas. Utilizaram-se as concentrações de 0,0; 5,4; 10,8; 21,6; e 43,2 $\mu \mathrm{g} \mathrm{L}^{-1}$ do ingrediente ativo do glyphosate em meio YM líquido, o que corresponde, respectivamente, às doses de 0,0 ; 1,5; 3,0; 6,0 e 12,0 L ha-1 da formulação comercial com $36 \%$ de equivalente ácido.

A ativação das estirpes foi realizada em frascos erlenmeyer de $125 \mathrm{~mL}$ contendo $50 \mathrm{~mL}$ de meio YM líquido, mediante a inoculação das estirpes e incubação em agitador rotatório a $125 \mathrm{rpm}$ e temperatura de $25^{\circ} \mathrm{C}$ por três dias. Após o crescimento, uma alíquota de $15 \mu \mathrm{L}$ das estirpes foi inoculada em placas de ELISA de 96 células com capacidade volumétrica de $300 \mu \mathrm{L}$, contendo a mistura estéril de $180 \mu \mathrm{L}$ de meio YM líquido (1,33 vez concentrado) e $60 \mu \mathrm{L}$ da solução do herbicida. Em seguida, as placas foram incubadas no escuro, a $28^{\circ} \mathrm{C}$, de onde foram retiradas somente para as leituras de densidade ótica (DO), sendo imediatamente recolocadas nesse local até o final das leituras. O crescimento das estirpes foi avaliado pela leitura da DO a $560 \mathrm{~nm}$ em espectrofotômetro (Titertek Multiskan Plus MKII, New York, USA), em intervalos de quatro horas nas primeiras 24 horas e, após, de 12 horas até a estabilização do crescimento, que ocorreu 126 horas após o início da incubação.

Os dados quantitativos foram analisados por regressão para a geração das curvas de crescimento. A comparação de médias para as variáveis qualitativas foi feita pelo teste de Tukey, a 5\% de probabilidade. 


\section{RESULTADOS E DISCUSSÃO}

O crescimento das três estirpes de Bradyrhizobium foi reduzido em todas as concentrações avaliadas do princípio ativo do glyphosate no meio de cultura com o aumento do tempo de incubação (Figuras 1, 2 e 3), demonstrando que a presença de pequenas concentrações deste herbicida é suficiente para inibir o crescimento do Bradyrhizobium. Há relatos de redução média de 61\% no crescimento de várias estirpes de Bradyrhizobium que haviam crescido em meio de cultura contendo o ingrediente ativo do glyphosate (Zablotowicz \& Reddy, 2004).

A estirpe SEMIA 587 teve seu crescimento inibido em 34,56\% na menor concentração do glyphosate (Figura 1 e Tabela 1). Com o aumento das concentrações, o crescimento foi sendo progressivamente inibido, não havendo, no entanto, diferenças entre as duas maiores concentrações, indicando que em 21,6 $\mu \mathrm{g} \mathrm{L}^{-1}$ já pode ter havido graves prejuízos ao crescimento do rizóbio, uma vez que a presença do dobro da concentração do herbicida não resultou em maiores reduções do crescimento.

Na menor concentração avaliada, a estirpe SEMIA 5019 reduziu seu crescimento em $29,25 \%$, não diferindo estatisticamente da concentração subsequente (Figura 2 e Tabela 1). Nas duas maiores concentrações houve redução progressiva do crescimento, demonstrando que essa estirpe conseguiu manter o crescimento próximo de $70 \%$ do controle na presença de $10,8 \mu \mathrm{g} \mathrm{L}^{-1}$, tendo a presença de maiores concentrações do glyphosate resultado ainda em maior redução de crescimento.

A estirpe SEMIA 5079 teve a menor redução de crescimento na concentração mais baixa de glyphosate e, assim

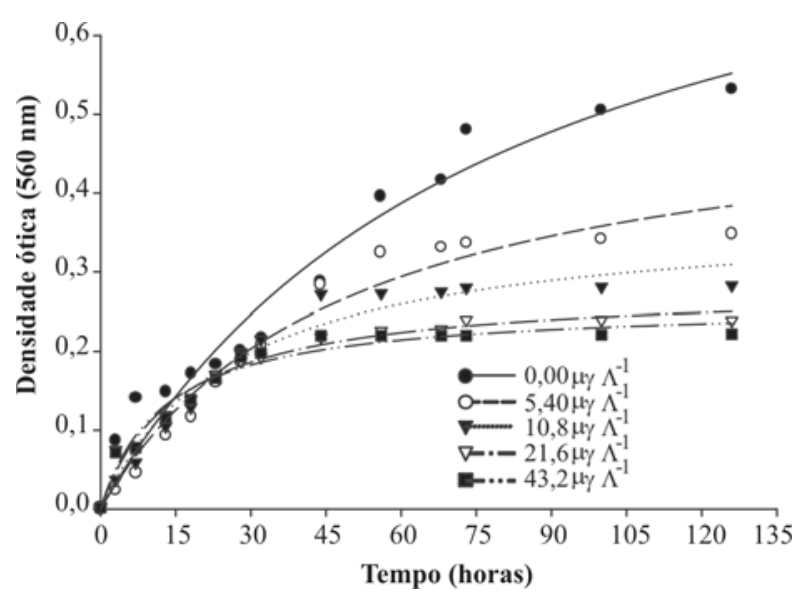

Figura 1. Crescimento da estirpe de Bradyrhizobium elkanii SEMIA 587 em diferentes concentrações $(\mathrm{H})$ de glyphosate, durante 126 horas de incubação. Viçosa, 2005. Equações das curvas de crescimento: $[0,0: \hat{\mathrm{Y}}=0,0113 \mathrm{H} /(1+0,0126 \mathrm{H}), \mathrm{R} 2=0,96]$; [5,4: $\hat{\mathrm{Y}}=0,0110 \mathrm{H} /(1+0,0206 \mathrm{H}), \mathrm{R} 2=0,97] ;[10,8: \hat{\mathrm{Y}}=0,0140 \mathrm{H} /$ $(1+0,0375 \mathrm{H}), \mathrm{R} 2=0,97] ;[21,6: \hat{\mathrm{Y}}=0,0185 \mathrm{H} /(1+0,0662 \mathrm{H})$, $\mathrm{R} 2=0,98] ;[$ 43,2: $\hat{\mathrm{Y}}=0,0207 \mathrm{H} /(1+0,0798 \mathrm{H}), \mathrm{R} 2=0,97]$. como a SEMIA 5019, não houve diferença estatística de crescimento em relação à concentração subsequente (Figura 3 e Tabela 1). Com o aumento da concentração para 21,6 $\mu \mathrm{g} \mathrm{L} \mathrm{L}^{-1}$, essa estirpe reduziu o seu crescimento em somente $27,66 \%$ em relação ao controle, demonstrando que conseguiu manter um crescimento próximo a $70 \%$ nessa concentração. Porém, a concentração de $43,2 \mu \mathrm{g} \mathrm{L}-$ ${ }^{1}$ glyphosate no meio de cultura reduziu drasticamente o crescimento dessa estirpe.

Nas curvas de crescimento apresentadas nas Figuras 1, 2 e 3 é possível observar que o efeito inibitório do

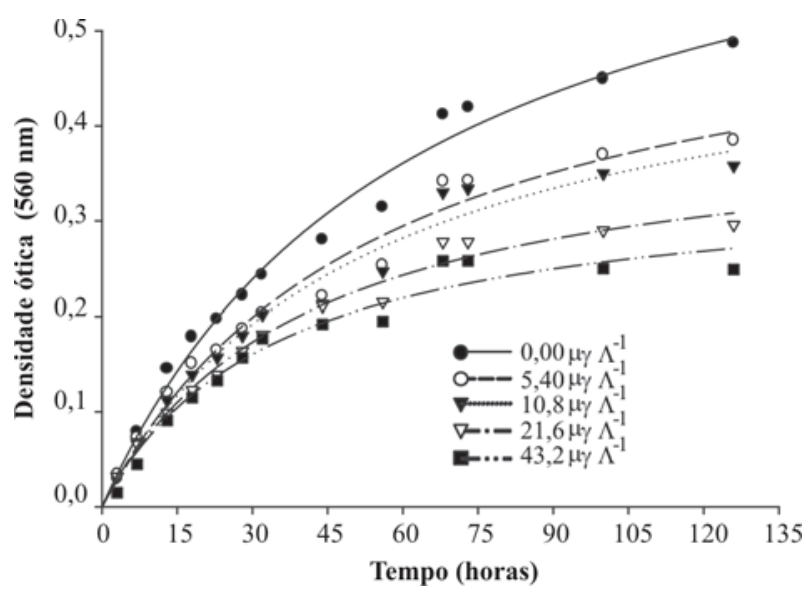

Figura 2. Crescimento da estirpe de Bradyrhizobium elkanii SEMIA 5019 em diferentes concentrações (H) de glyphosate, durante 126 horas de incubação. Viçosa, 2005. Equações das curvas de crescimento: [0,0: $\hat{Y}=0,0118 \mathrm{H} /(1+0,0160 \mathrm{H}), \mathrm{R} 2=0,99]$; [5,4: $\hat{\mathrm{Y}}=0,0102 \mathrm{H} /(1+0,0179 \mathrm{H}), \mathrm{R} 2=0,98] ;[10,8: \hat{\mathrm{Y}}=0,0100 \mathrm{H} /$ $(1+0,0189 \mathrm{H}), \mathrm{R} 2=0,98]$; [21,6: $\hat{\mathrm{Y}}=0,0100 \mathrm{H} /(1+0,0245 \mathrm{H}), \mathrm{R} 2$ $=0,99] ;[43,2: \hat{\mathrm{Y}}=0,0100 \mathrm{H} /(1+0,0289 \mathrm{H}), \mathrm{R} 2=0,97)]$.

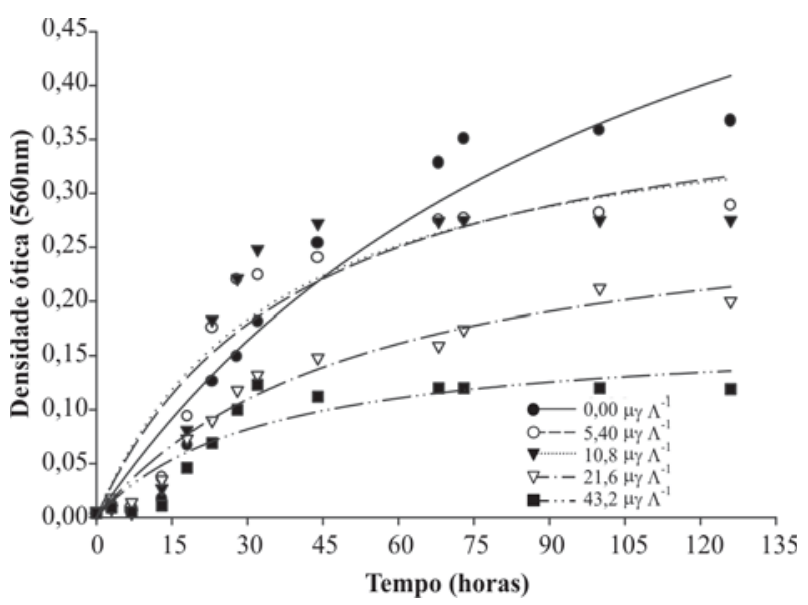

Figura 3. Crescimento da estirpe de Bradyrhizobium japonicum SEMIA 5079 em diferentes concentrações $(\mathrm{H})$ de glyphosate, durante 126 horas de incubação. Viçosa, 2005. Equações das curvas de crescimento: [0,0: $\left.\hat{Y}=0,0096 \mathrm{H} /(1+0,0090 \mathrm{H}), \mathrm{R}^{2}=0,94\right]$; [5,4: $\left.\hat{\mathrm{Y}}=0,0105 \mathrm{H} /(1+0,0252 \mathrm{H}), \mathrm{R}^{2}=0,89\right] ;[10,8: \hat{\mathrm{Y}}=0,0112 \mathrm{H} /$ $\left.(1+0,0277 \mathrm{H}), \mathrm{R}^{2}=0,84\right]$; [21,6: $\hat{\mathrm{Y}}=0,0050 \mathrm{H} /(1+0,0131 \mathrm{H}), \mathrm{R}^{2}=$ 0,97]; [43,2: $\left.\hat{\mathrm{Y}}=0,0052 \mathrm{H} /(1+0,0303 \mathrm{H}), \mathrm{R}^{2}=0,83\right]$. 
Tabela 1. Crescimento relativo (\%) de três estirpes de Bradyrhizobium após 126 horas de incubação em meio de cultura YM contendo cinco concentrações de glyphosate $\left(\mathrm{mg} \mathrm{L}^{-1}\right)$. Viçosa, 2005

\begin{tabular}{lccc}
\hline $\begin{array}{l}\text { Concentrações } \\
\text { de glyphosate }\end{array}$ & SEMIA 587 & SEMIA 5019 & SEMIA 5079 \\
\hline 0,0 & $100,00 \mathrm{aA}$ & $100,00 \mathrm{aA}$ & $100,00 \mathrm{aA}$ \\
5,4 & $65,44 \mathrm{bC}$ & $70,75 \mathrm{bB}$ & $81,58 \mathrm{bA}$ \\
10,8 & $53,20 \mathrm{cC}$ & $66,43 \mathrm{bB}$ & $78,52 \mathrm{bA}$ \\
21,6 & $44,96 \mathrm{dC}$ & $51,94 \mathrm{cB}$ & $72,34 \mathrm{cA}$ \\
43,2 & $41,70 \mathrm{dA}$ & $41,03 \mathrm{dA}$ & $42,23 \mathrm{dA}$ \\
\hline
\end{tabular}

${ }^{1}$ Médias seguidas de uma mesma letra, maiúscula na linha e minúscula na coluna, não diferem entre si pelo teste de Tukey a 5\% de probabilidade de erro.

glyphosate manisfestou-se pela redução da fase logarítmica de crescimento das estirpes avaliadas. De modo geral, observa-se que quanto maior a concentração de glyphosate menor a fase logarítmica e maior a fase estacionária. Exemplo típico desse comportamento foi observado com a estirpe SEMIA 587 (Figura 1). Na ausência do glyphosate no meio de cultura, a fase logarítmica de crescimento teve duração aproximada de 72 horas. Porém, na presença das concentrações de 5,4; 10,8; e 21,6 $\mu \mathrm{g} \mathrm{L}^{-1}$ do ingrediente ativo do glyphosate em meio YM líquido as fases logarítmicas de crescimento foram reduzidas para 48, 36 e 24 horas, respectivamente, tendo na concentração 43,2 $\mu \mathrm{g} \mathrm{\textrm {L } ^ { - 1 }}$ a duração da fase logarítmica não diferido da concentração de 21,6 $\mu \mathrm{g} \mathrm{L}^{-1}$ e também teve duração aproximada de somente 24 horas. Como a fase estacionária apresenta crescimento nulo ou muito baixo, essa redução da fase logarítmica foi responsável pelos menores crescimentos relativos observados na presença das diferentes concentrações de glyphosate após 126 horas de incubação (Tabela 1).

A toxicidade do glyphosate às células do rizóbio pode ser atribuída a três efeitos: i) inibição da enzima EPSPs e consequente inabilidade celular para a síntese de aminoácidos aromáticos; ii) gasto excessivo de energia (adenosina trifosfato e fosfoenolpiruvato) para a produção de ácidos hidroxibenzóicos, como forma de “consumo” do shiquimato acumulado na célula; e iii) toxicidade dos ácidos hidroxibenzóicos produzidos a partir do shiquimato (Zablotowicz \& Reddy, 2004). Assim, a redução da atividade da EPSPs pelo glyphosate diminui a produção de triptofano, tirosina e fenilalanina, o que compromete a síntese de proteínas e, por consequência, o crescimento celular (Caldwell, 1999). Esse efeito é comprovado quando a adição desses aminoácidos ao meio de cultura contendo o glyphosate permite que as células do rizóbio retomem o crescimento (Liu et al., 1991).

Por outro lado, quando a adição dos aminoácidos não resulta na retomada do crescimento, é provável que a inibição causada pelo glyphosate esteja relacionada ao gasto excessivo de energia para a produção de ácidos hidroxibenzóicos e a subsequente toxicidade desses às células do rizóbio. Estirpes de Bradyrhizobium crescidas na presença do glyphosate apresentaram um incremento na concentração do shiquimato intracelular de até 200 vezes superior ao controle (Hernandez et al., 1999). O ácido protocatecóico apresentou valores 130 vezes maiores nas células do Bradyrhizobium que havia crescido na presença do glyphosate, se comparado aos valores observados quando o rizóbio havia crescido sem esse herbicida no meio de cultura (Moorman, 1986).

O aumento da concentração de glyphosate no meio de cultura reduziu exponencialmente o crescimento das estirpes de Bradyrhizobium (Figura 4), demonstrando que houve grande redução de crescimento em baixas concentrações do herbicida. Este comportamento pode indicar que pequenos aumentos na concentração de glyphosate nos nódulos das plantas de soja RR podem resultar em decréscimos significativos da multiplicação intrarradicular dos rizóbios, que é uma das etapas de grande importância para a formação dos nódulos (Prell \& Poole, 2006).

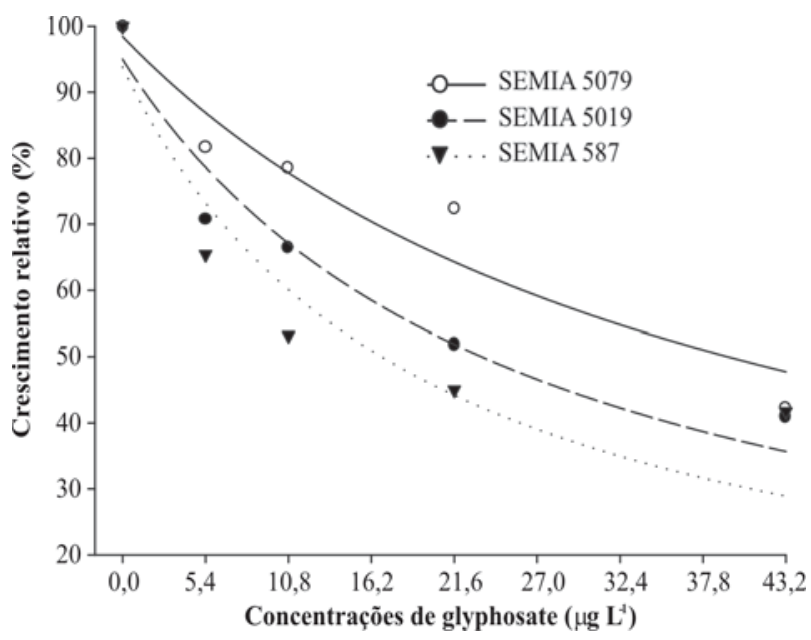

Figura 4. Crescimento relativo das estirpes de Bradyrhizobium elkanii SEMIA 587 e SEMIA 5019 e de B. japonicum SEMIA 5079 na presença de diferentes concentrações $(\mathrm{H})$ de glyphosate no meio de cultura, após 126 horas de incubação. Viçosa, 2005. Equações das curvas: [SEMIA 587: $\hat{Y}=501,20 /(5,3432+H)$, $\left.\mathrm{R}^{2}=0,89\right]$; [SEMIA 5019: $\left.\hat{\mathrm{Y}}=684,46 /(7,2046+\mathrm{H}), \mathrm{R}^{2}=0,95\right]$; [SEMIA 5079: $\hat{\mathrm{Y}}=1112,42 /(11,3016+\mathrm{H}), \mathrm{R}^{2}=0,93$ ]. 
Com o crescimento relativo das três estirpes nas concentrações de 5,4; 10,8; e 21,6 $\mu \mathrm{g} \mathrm{L}^{-1}$ de glyphosate (Tabela 1), verificou-se que a estirpe SEMIA 587 foi a mais sensível a esse herbicida, seguida da estirpe SEMIA 5019, que apresentou comportamento intermediário, e da estirpe SEMIA 5079, que demonstrou ser a mais tolerante ao herbicida. Tal fato pode indicar que a sensibilidade ao glyphosate pode ser uma característica interespecífica. Schulz et al. (1985) também observaram variações na taxa de crescimento de 12 diferentes bactérias em meio de cultura contendo a mesma concentração desse herbicida. De forma a elucidar esse comportamento, as enzimas EPSPs das bactérias foram extraídas, sendo verificado que a inibição da atividade de cada enzima ocorria em diferentes concentrações do glyphosate. Isso indicou que a sensibilidade das estirpes ao herbicida é consequência da sensibilidade diferencial da enzima EPSPs ao glyphosate. Outra hipótese que pode explicar a sensibilidade diferencial é a capacidade de excreção do shiquimato e dos ácidos hidroxibenzóicos, que se acumulam nas células em decorrência do bloqueio da EPSPs. Já foi reportado que os isolados mais tolerantes ao glyphosate apresentaram maior capacidade de excreção desses ácidos para o meio de cultura, podendo essa ação se constituir num mecanismo de redução da toxicidade intracelular das elevadas concentrações do shiquimato e ácido hidroxibenzóico (Schulz et al., 1985; Moorman et al., 1992; Hernandez et al., 1999).

No entanto, na maior concentração do glyphosate a redução de crescimento das três estirpes foi próxima a $60 \%$ do controle, não havendo diferenças entre elas (Tabela 1). Isto indica que a tolerância dessas estirpes ao herbicida é relativa, ou seja, em concentrações elevadas do glyphosate as diferenças de crescimento entre elas desaparecem, pois mesmo as estirpes mais tolerantes têm seu crescimento severamente reduzido.

Com base nestes resultados, os quais demonstram a redução significativa do crescimento de estirpes de Bradyrhizobium pelo glyphosate, sugere-se a realização de experimentos em casa de vegetação e no campo para avaliar os efeitos do glyphosate na nodulação e na fixação de $\mathrm{N}_{2}$ dos cultivares de soja RR atualmente utilizadas no Brasil, além da possível existência de sensibilidade diferencial na interação planta-microrganismo.

\section{CONCLUSÕES}

Todas as concentrações do ingrediente ativo do glyphosate reduzem significativamente o crescimento das estirpes de Bradyrhizobium avaliadas, sendo essa redução tanto maior quanto maior a concentração do herbicida presente no meio de cultura. As estirpes de Bradyrhizobium apresentam sensibilidade diferencial às menores concentrações do glyphosate, sendo possível determinar a seguinte ordem de sensibilidade: SEMIA 587 $>$ SEMIA 5019 > SEMIA 5079. Tal sensibilidade diferencial é dependente da concentração do ingrediente ativo do glyphosate no meio de cultura, tendo, na maior concentração avaliada, todas as estirpes seu crescimento severamente reduzido.

\section{AGRADECIMENTOS}

À Embrapa Agrobiologia, pelo fornecimento das estirpes de Bradyrhizobium e ao CNPq e à Syngenta Proteção de Cultivos, pelo apoio financeiro.

\section{REFERÊNCIAS}

Arruda JS, Lopes NF \& Moura AB (2001) Behavior of Bradyrhizobium japonicum strains under different herbicide concentrations. Planta Daninha, 19:111-117.

Borges AC, Guimarães WV, Muchovej RMC \& Gonzales GR (1990) Resistance of Bradyrhizobium japonicum strains to different fungicides and herbicides. World Journal of Microbiology and Biotechnology, 6:428-430.

Buchanan BB, Gruissem W \& Jones RL (2000) Biochemistry and molecular biology of plants. Rockville, ASPP. 1367p.

Caldwell DR (1999) Microbial physiology and metabolism. $2^{\text {a }}$ ed. Belmont, Star. 403p.

Eberbach PL \& Douglas LA (1989) Herbicide effects on the growth and nodulation potential of Rhizobium trifolii with Trifolium subterraneum. Plant and Soil, 119:15-23.

Embrapa (2009) Soja - dados econômicos. Disponível em: <http:/ /www.cnpso.embrapa.br/index.php?op_page=294\&cod_pai=17>. Acessado em: 21 de maio de 2009.

Hernandez A, Garcia-Plazaola JI \& Becerril JM (1999) Glyphosate effects on phenolic metabolism of nodulated soybean (Glycine $\max$ L. Merr.). Journal of Agricultural Food and Chemistry, 47:2920-2925.

King AC, Purcell, LC \& Vories ED (2001) Plant growth and nitrogenase activity of glyphosate-tolerant soybean in response to glyphosate applications. Agronomy Journal, 93:179-186.

Liu CM, McLean PA, Sookdeo CC \& Cannon FC (1991) Degradation of the herbicide glyphosate by members of the family Rhizobiaceae. Applied and Environmental Microbiology, 57:1799-1804.

Mallik MAB \& Tesfai K (1985) Pesticidal effect on soybeanrhizobia symbiosis. Plant and Soil, 85:33-41.

Moorman TB (1986) Effects of herbicides on the survival of Rhizobium japonicum strains. Weed Science, 34:628-633.

Moorman TB, Becerril JM, Lydon J \& Duke SO (1992) Production of hydroxybenzoic acids by Bradyrhizobium japonicum strains after treatment with glyphosate. Journal of Agricultural Food and Chemistry, 40:289-293.

Padgette SR, Kolacz KH, Delannay X, Re DB \& La Vallee BJ (1995) Development, identification, and characterization of a glyphosate-tolerant soybean line. Crop Science, 35:1451-1461.

Prell J \& Poole P (2006) Metabolic changes of rhizobia in legume nodules. Trends in Microbiology, 14:161-168.

Reddy KN, Hoagland RE \& Zablotowicz RM (2000) Effect of glyphosate on growth, chlorophyll content and nodulation in glyphosate-resistant soybeans (Glycine max) varieties. Journal of New Seeds, 2:37-52. 
Reddy KN \& Zablotowicz RM (2003) Glyphosate-resitant soybean response to various salts of glyphosate and glyphosate accumulation in soybean. Weed Science, 51:496-502.

Santos JB, Ferreira EA, Kasuya MCM, Da Silva AA \& Procopio SDO (2005) Tolerance of Bradyrhizobium strains to glyphosate formulations. Crop Protection, 24:543-547.

Schulz A, Krüper A \& Amrhein N (1985) Differential sensitivity of bacterial 5-enolpyruvylshikimate-3-phosphate synthases to the herbicide glyphosate. FEMS Microbiology Letters, 28:297-301.
Zabaloy MC \& Gómez MA (2005) Diversity of rhizobia isolated from an agricultural soil in Argentina based on carbon utilization and effects of herbicides on growth. Biology and Fertility of Soils, 42:83-88.

Zablotowicz RM \& Reddy KN (2004) Impact of glyphosate on the Bradyrhizobium japonicum symbiosis with glyphosateresistant transgenic soybean: a minireview. Journal of Environmental Quality, 33:825-831. 